\title{
On using the seasonal cycle to interpret extratropical temperature changes since 1950
}

\section{Citation}

McKinnon, Karen A., and Peter Huybers. 2014. "On Using the Seasonal Cycle to Interpret Extratropical Temperature Changes Since 1950." Geophysical Research Letters 41 (13): 46764684. doi:10.1002/2014gl060404.

\section{Published Version}

doi:10.1002/2014gl060404

\section{Permanent link}

http://nrs.harvard.edu/urn-3:HUL.InstRepos:25667321

\section{Terms of Use}

This article was downloaded from Harvard University's DASH repository, and is made available under the terms and conditions applicable to Other Posted Material, as set forth at http:// nrs.harvard.edu/urn-3:HUL.InstRepos:dash.current.terms-of-use\#LAA

\section{Share Your Story}

The Harvard community has made this article openly available.

Please share how this access benefits you. Submit a story.

\section{Accessibility}




\section{Geophysical Research Letters}

\section{RESEARCH LETTER \\ 10.1002/2014GL060404 \\ On using the seasonal cycle to interpret extratropical temperature changes since 1950}

Key Points:

- A simple model represents

land-ocean interactions from

wind patterns

- The model is tuned to the seasonal cycle of temperature

- Predictions capture significant structure in decadal warming patterns

Supporting Information:

- Readme

- Text S1

- Figure S1

- Figure S2

- Figure S3

Correspondence to:

K. A. McKinnon,

mckinnon@fas.harvard.edu

Citation:

McKinnon, K. A., and P. Huybers (2014), On using the seasonal cycle to interpret extratropical temperature changes since 1950, Geophys. Res. Lett., 41, doi:10.1002/2014GL060404.

Received 2 MAY 2014 Accepted 10 JUN 2014

Accepted article online 12 JUN 2014

\author{
Karen A. McKinnon ${ }^{1}$ and Peter Huybers ${ }^{1}$ \\ ${ }^{1}$ Department of Earth and Planetary Sciences, Harvard University, Cambridge, Massachusetts, USA
} seasonal cycle.

\section{Introduction}

Abstract Extratropical near-surface air temperature variability is explored on three different time scales: the seasonal cycle, observed changes in temperature since 1950, and the equilibrium response to increasing $\mathrm{CO}_{2}$ in an atmospheric general circulation simulation with fixed sea surface temperatures. Exploration is undertaken using an energy balance model (EBM) that parameterizes advective land-ocean heat fluxes. The EBM is tuned only to the climatological seasonal cycle yet captures $47 \%$ of the variability in observed multidecadal temperature changes in the extratropics and $78 \%$ of the variability in the equilibrated model simulation. The subseasonal time scale of atmosphere-surface heat fluxes explains, at least in the context of this EBM, the ability to infer patterns of multidecadal change using information primarily drawn from the

The importance of ocean heat uptake in influencing patterns of temperature variability is well established. These patterns include the amplitude and phase of the seasonal cycle of surface temperature [North and Coakley, 1979; North et al., 1981; McKinnon et al., 2013], internally generated surface temperature variability [Kim and North, 1991], and transient surface temperature changes in response to increased radiative forcing [Stouffer et al., 1989; Manabe et al., 1991; Kim et al., 1992]. The common influence of ocean heat uptake amongst seasonal, interannual, and decadal time scales of temperature variation suggests that the observed response at one time scale may inform about the others. Indeed, the amplitude of the seasonal cycle in surface temperature has previously been used as a predictor for equilibrium climate sensitivity across an ensemble of general circulation models [Knutti et al., 2006], and the magnitude of the seasonal cycle is a good predictor of the magnitude of decadal variability in regional surface temperatures [Huybers and Curry, 2006].

That there are common controls on surface temperature variability for the seasonal cycle and longer time scales has previously been demonstrated using an energy balance model (EBM), wherein atmospheric heat transport was parameterized as a diffusive process [Kim and North, 1991; Kim et al., 1992]. Here we revisit this topic from the standpoint of a longer instrumental record and an EBM that permits for analytical solutions. Furthermore, as opposed to the diffusive and isotropic representation of horizontal heat fluxes used in the earlier EBM studies, heat transport is parameterized based on mean atmospheric circulation, allowing for anisotropy due to the climatological wind patterns.

The EBM is written in a minimalist manner so as to isolate the influence of advection of heat between land and ocean on surface temperature patterns. Excess heat not realized as a temperature increase is stored in the ocean. While this approach ignores many additional important processes, such as changes in meridional heat transport, the spatial structure of perturbative radiative forcing, and spatial and temporal variability in mixed layer depth, it allows us to isolate the effect of ocean heat storage on temperature variability. The model is presented and minimally tuned to the seasonal cycle (section 2), shown to give accurate predictions at longer time scales using equilibrium results from a general circulation model (GCM) with fixed sea surface temperatures (section 3), and then compared to observed temperature variations over recent decades (section 4). The skill_or lack thereof-of the EBM is used as a metric to assess the importance of advective heat fluxes and ocean heat uptake in influencing surface temperature as compared to other climate processes that are excluded from the model. 


\section{Amplitude of the Seasonal Cycle in Surface Temperature}

\subsection{EBM Formulation}

The near-surface air temperature anomaly (hereafter simply "temperature"), $T_{i, j}$, is modeled as a mixture between land and ocean temperatures, weighted by a mixing parameter, $m_{i, j}$

$$
T_{i, j}=m_{i, j} T_{\text {land }}+\left(1-m_{i, j}\right) T_{\text {ocean }} .
$$

"Land" and "ocean" refer to the end-member cases where the heat flux divergence is zero, so the end-members are in local radiative equilibrium. The indices $i, j$ indicate spatial dependence. These end-members are modeled using two linearized energy balance models:

$$
C_{\text {land }} \frac{\mathrm{d} T_{\text {land }}}{\mathrm{d} t}=R+\lambda T_{\text {land }}
$$

and

$$
C_{\text {ocean }} \frac{\mathrm{d} T_{\text {ocean }}}{\mathrm{d} t}=R+(\lambda-\kappa) T_{\text {ocean }}
$$

where $C$ is heat capacity, with $C_{\text {land }}<C_{\text {ocean }}, R$ is a perturbative radiative forcing, $\lambda$ is a feedback parameter, and $\kappa$ is a linear diffusivity that controls the rate of heat uptake by the deep ocean. Parameters lacking subscripts are constant in space. Ocean temperature, $T_{\text {ocean }}$, represents the mixed layer, and the deep ocean is assumed to have infinite heat capacity for the scenarios considered here.

Energy balance equations similar to equations (2) and (3) are more typically applied with respect to the global mean [e.g., Wigley and Schlesinger, 1985; Raper et al., 2002; Gregory and Forster, 2008]; here the end-members are reflective neither of the global mean nor of the average land and ocean temperatures. Instead, each model equation captures the temperature response for land or ocean if each was controlled only by its heat capacity, the feedback parameter, and-in the case of the ocean-heat uptake by the deep ocean.

Local temperatures, $T_{i, j}$, are then expressed as

$$
\begin{gathered}
C_{\text {land }} \frac{\mathrm{d} T_{i, j}}{\mathrm{~d} t}=R+\lambda T_{i, j}-H_{i, j}, \\
H_{i, j}=\left(1-m_{i, j}\right)\left[\left(C_{\text {ocean }}-C_{\text {land }}\right) \frac{\mathrm{d} T_{\text {ocean }}}{\mathrm{d} t}+\kappa T_{\text {ocean }}\right] .
\end{gathered}
$$

In this formulation, temperature is modeled as a fast, land-like response to forcing that is damped by the horizontal, dominantly zonal heat flux divergence, $H_{i, j}$, due to atmospheric advection. The magnitude of damping is a function of Relative Land Influence, $m_{i, j}$. Relative Land Influence is a scalar measure of the relative magnitude of atmospheric heat fluxes from land as compared to ocean at a given location and is calculated from an ensemble of Lagrangian air parcel back trajectories. The parcel trajectories are simulated using the Hybrid Single-Particle Lagrangian Integrated Trajectory model [Draxler and Hess, 1997, 1998; Draxler, 1997] and the meteorological fields from National Centers for Environmental Prediction -Department of Energy (NCEP-DOE) reanalysis [Kanamitsu et al., 2002]. Values from zero to one grade from purely marine to purely continental influence (Figure S1 in the supporting information). Further details regarding Relative Land Influence can be found in McKinnon et al. [2013] and the supporting information. The model is written such that the net diverged heat is implicitly stored in the mixed layer (first term on the right-hand side of equation (5)) and deep ocean (second term on the right-hand side of equation (5)).

\subsection{Application to the Seasonal Cycle}

To model the extratropical seasonal cycle, we prescribe a sinusoidal forcing function, $R$, with annual frequency, $\omega$. The seasonal cycle is negligibly influenced by the deep ocean in the EBM, so the value of $\kappa$ in equation (3) is set to zero for simplicity. Consistent with this assumption, the seasonal time scale results are insensitive to the choice of $\kappa$. The amplitude and phase of $R$ vary in latitude, so we examine the annual component of temperature normalized by that of the forcing, i.e., the gain [Stine et al., 2009]. Annual components of temperature and forcing are calculated as the magnitude of the once-per-year Fourier component [Thomson, 1995]. Equations (4) and (5) yield a gain, $G_{i, j}$, of

$$
G_{i, j}=\left[\frac{\lambda^{2}+\omega^{2}\left(C_{\text {land }}\left(1-m_{i, j}\right)+C_{\text {ocean }} m_{i, j}\right)^{2}}{\left(\lambda^{2}+C_{\text {land }}^{2} \omega^{2}\right)\left(\lambda^{2}+C_{\text {ocean }}^{2} \omega^{2}\right)}\right]^{1 / 2} .
$$


Table 1. Model Parameters for the EBM in the Three Different Scenarios ${ }^{\mathrm{a}}$

\begin{tabular}{|c|c|c|c|}
\hline Name & Symbol & Value & Units \\
\hline Land heat capacity & $C_{\text {land }}$ & 2 & meters water equivalent (mwe) \\
\hline Ocean heat capacity & $C_{\text {ocean }}$ & 76 & mwe \\
\hline Angular frequency & $\omega$ & $2 \pi$ (year) $^{-1}$ & year $^{-1}$ \\
\hline Radiative forcing $\left(2 \times \mathrm{CO}_{2}\right)$ & $R_{2 x}$ & 3.48 & $\mathrm{~W} \mathrm{~m}^{-2}$ \\
\hline Radiative forcing rate (before 1982) & $\beta_{1}$ & 0.06 & $W \mathrm{~m}^{-2}(\text { decade })^{-1}$ \\
\hline Radiative forcing rate (after 1982) & $\beta_{2}$ & 0.53 & $\mathrm{~W} \mathrm{~m}^{-2}$ (decade) $^{-1}$ \\
\hline Meters water equivalent & mwe & $4.18 \times 10^{6}$ & $\mathrm{~J} \mathrm{~m}^{-2} \mathrm{~K}^{-1}$ \\
\hline Scaling parameter for Relative Land Influence & $k$ & $0.52 \pm 0.01$ & (unitless) \\
\hline Seasonal cycle feedback parameter & $\lambda_{\text {seasonal }}$ & $-2.48 \pm 0.15$ & $W m^{-2} K^{-1}$ \\
\hline Fixed SST equilibrium feedback parameter & $\lambda_{\mathrm{AM} 2.1}$ & $-2.09 \pm 0.09$ & $W m^{-2} K^{-1}$ \\
\hline Multidecadal change feedback parameter & $\lambda_{\text {HadCRUT4 }}$ & $-0.57 \pm 0.04$ & $W m^{-2} K^{-1}$ \\
\hline Linearized ocean diffusivity & $\kappa$ & $7.69 \pm 2.02$ & $W m^{-2} K^{-1}$ \\
\hline
\end{tabular}

a Parameters are inferred from fitting the model to the data, via minimizing the mean squared deviations across gridboxes, and are shown with their $95 \%$ confidence intervals.
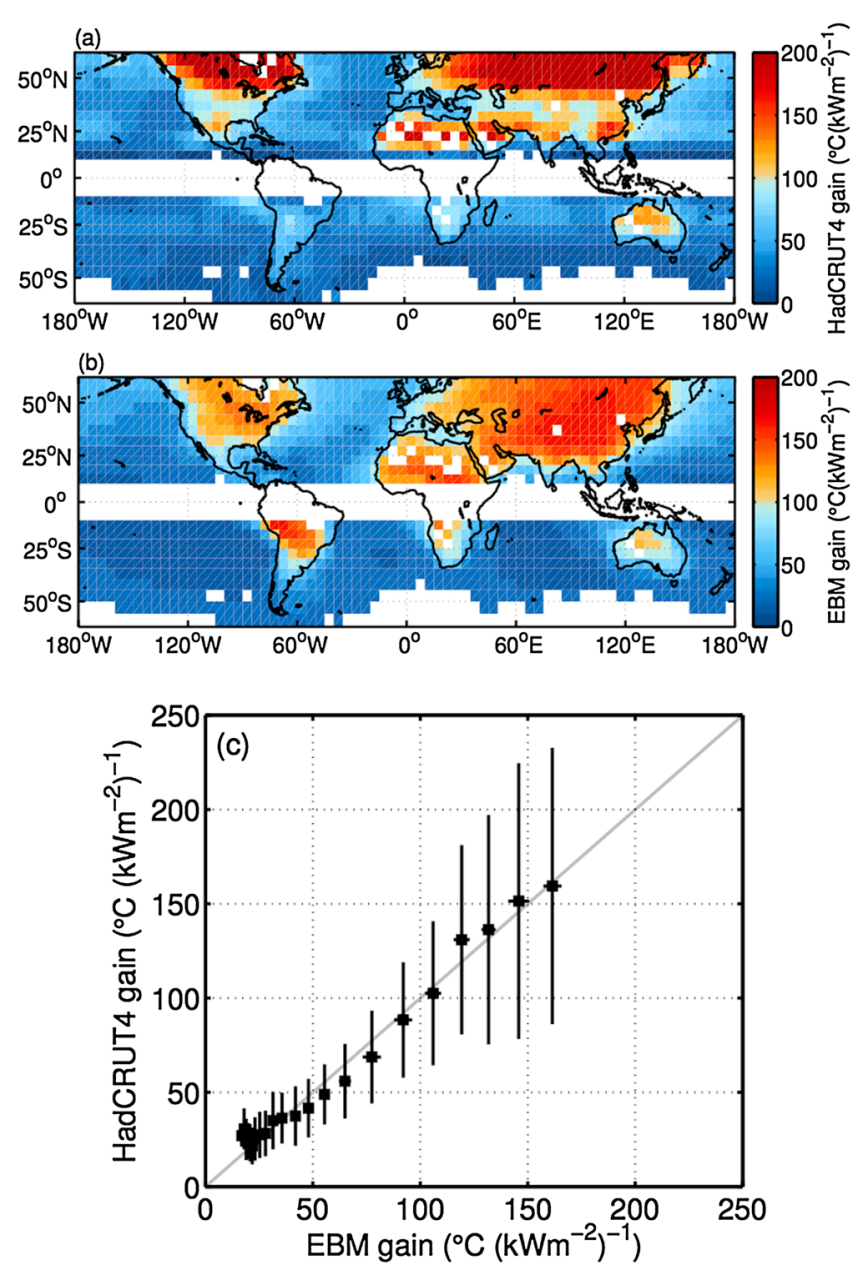

Figure 1. EBM fit to the seasonal cycle. (a) Gain of the observed seasonal cycle from the HadCRU climatology. (b) Gain predicted by the EBM. (c) Observed gain (vertical axis) compared to modeled gain (horizontal axis) after binning. The squares show the mean of the bin, whereas the whiskers show one standard deviation across the gridboxes within the bin. Number of bins is assigned as a function of number of gridboxes, $n$, according to the Rice Rule as $\left\lceil 2 n^{1 / 3}\right\rceil$, and there is approximately the same number of gridboxes in each bin.
A related expression is obtained for the phase offset, or lag, between the forcing and the temperature response. Heat capacities, $C_{\text {land }}$ and $C_{\text {ocean }}$, are respectively set to 2 and 76 meters of water equivalent, consistent with previously used values [McKinnon et al., 2013]. All parameter values are given in Table 1.

To estimate gain from observations (Figure 1a), we use the Hadley Centre monthly temperature climatology at $5^{\circ} \times 5^{\circ}$ resolution [Morice et al., 2012], scaled by the seasonal forcing. The forcing is the sum of two annual period terms: (1) the top-of-the-atmosphere (TOA) solar forcing, scaled by a coalbedo, and (2) the seasonal cycle in meridional heat flux convergence. We explicitly include meridional heat flux convergence in the forcing because it is not otherwise parameterized in the model but acts to damp the seasonal cycle in heating [Donohoe and Battisti, 2013] and, therefore, should also be accounted for when estimating gain. Note that the availability of observationally based estimates of seasonal heat flux convergence and our approach of using the seasonal cycle to tune the EBM is distinct from later applications of the EBM, when it is used to predict anomalies in temperature at longer time scales, and when anomalies in heat flux convergence are not included. 
Both the TOA solar forcing and the coalbedo are from the Clouds and Earth's Radiant Energy System Energy Balanced and Filled climatology product [Loeb et al., 2009]. Meridional heat flux convergence is from the analysis of Fasullo and Trenberth [2008]. The amplitude and phase of the forcing varies as a function of latitude but is constant in longitude, such that all zonal structure in the EBM is due to structure in Relative Land Influence.

Analysis is restricted to the extratropics ( $10-60^{\circ}$ in both hemispheres) due to weak once-per-year solar influence relative to other processes in the deep tropics [Sobel et al., 2001] and the combination of fewer data and strong local feedbacks [Hwang et al., 2011] in the high latitudes. Locations where less than 50\% of the variance in the monthly climatology is explained by an annual period sinusoid are also excluded from all analyses. The remaining domain covers $64 \%$ of the global area. Estimation of the annual period components of temperature and forcing using daily rather than monthly values gives essentially the same results [McKinnon et al., 2013].

Two free scalar parameters are jointly adjusted to fit the EBM to the seasonal cycle. The first, $k$, scales the range of Relative Land Influence. Specifically, while the spatial pattern of Relative Land Influence is fixed from the analysis of the Lagrangian back trajectory ensemble (see supporting information), it spans an arbitrary range between zero and one. The scalar parameter, $k$, translates the unscaled values of Relative Land Influence, $m_{i, j}^{*}$ from equation (S1) to scaled ones, $m_{i, j}$ as $m_{i, j}=k m_{i, j}^{*}$. The scaled values allow for a proper allocation of local heat fluxes between outgoing longwave radiation, $\lambda T_{i, j}$, and heat flux divergence, $H_{i, j}$ (see equations (4) and (5)). The second free parameter is the feedback parameter, $\lambda$. The two parameters are jointly constrained (see Figure $2 \mathrm{~b}$ ) through minimizing the sum of squared deviations across gridboxes between the EBM and observations. Operationally, we use the MATLAB nonlinear fitting toolbox, which utilizes the Levenberg-Marquardt algorithm for minimization. The value of $k$ is fixed to the value found here in all subsequent analyses.

The EBM fit to the seasonal cycle indicates a feedback parameter value of $-2.48 \pm 0.15 \mathrm{Wm}^{-2} \mathrm{~K}^{-1}$, where a more negative $\lambda$ is associated with a smaller equilibrium temperature response to a given forcing. Uncertainties are $95 \%$ confidence intervals based on model fit to the data and do not include the effects of error in model choice or in the observational data. The gains predicted from the EBM and observed in the Hadley Centre data have a correlation of 0.81 across space (Figure 1). This correlation indicates that the model is largely capable of reproducing the seasonal climatology in the selected domain, but because we approach the seasonal cycle as a tool for model tuning, we do not make any claims as to the significance of the correlation.

\section{An Equilibrium Experiment}

To explore whether the seasonal results are also informative for longer time scale responses, we examine the annual mean temperature changes (Figure S2a) from a set of Geophysical Fluid Dynamics Laboratory AM2.1 model simulations [The GFDL Global Atmospheric Model Development Team, 2004]. The simulations begin in equilibrium with preindustrial $\mathrm{CO}_{2}$ concentrations. Sea surface temperatures (SSTs) are fixed to their original equilibrated values, then $\mathrm{CO}_{2}$ concentrations are doubled, and the model is integrated until it attains a new equilibrium, which occurs almost entirely within a model year. The fixed SST experiment allows us to examine temperature changes due to increasing $\mathrm{CO}_{2}$ in the end-member case where all temperature change is confined to the land and atmosphere, because the ocean adjustment time scale is effectively infinite. This maximizes the signal of differential land and ocean warming in response to increased radiative forcing.

Temperature change is calculated as the difference in annual average temperature between the control and the $2 \times \mathrm{CO}_{2}$ simulations, where 60 years of model output from three different simulations are used in the control average and 40 years from two different simulations are used in the $2 \times \mathrm{CO}_{2}$ average. We regrid the AM2.1 model output to the $5^{\circ}$ resolution of the Hadley temperature data.

Representation of the equilibrium near-surface air temperature change, $\Delta T_{i, j}$, due to land-ocean heat fluxes parameterized in the EBM, is particularly simple for a fixed SST model simulation. In this case, all changes in temperature are related to warming over land; warming over the ocean is due only to advection of heat from 
the land, as represented by Relative Land Influence. Using equations (4) and (5), this temperature change can be written as

$$
\Delta T_{i, j}=-\frac{R_{2 x}}{\lambda} m_{i, j}
$$

$R_{2 x}$ is the radiative forcing due to $\mathrm{CO}_{2}$ doubling, set at $3.48 \mathrm{Wm}^{-2}$ [Held et al., 2010]. Although $R_{2 x}$ is expected to have latitudinal structure, we use a single global mean value for the purpose of isolating the contribution of advective land-ocean heat fluxes to the pattern of warming. Unlike the seasonal cycle analysis, meridional heat flux convergence anomalies are not included or parameterized. The values of Relative Land Influence, $m_{i, j}$, are fixed from the seasonal cycle analysis, and the only adjustable parameter in the model is $\lambda$. As can be seen in equation (7), temperature change (Figure S2b) is expected to be linear in Relative Land Influence and have zero warming for zero Relative Land Influence. The feedback parameter can be calculated directly from the best fit line through the origin between $m_{i, j}$ and $\Delta T_{i, j}$ giving $\lambda=-2.09 \pm 0.09 \mathrm{Wm}^{-2} \mathrm{~K}^{-1}$.

The EBM predicts the majority of the equilibrium temperature structure in the AM2.1 model simulation ( $r=0.87$ and $p$ value $<0.01$, Figure S2). Model skill is not simply due to the land/ocean contrast in warming, as model predictions are independently significant over land ( $r=0.66$ and $p$ value $<0.01$ ) and ocean $(r=0.71$ and $p$ value $<0.01)$. Significance of these correlations is estimated using a Monte Carlo method whereby surrogate fields of Relative Land Influence are obtained using the Iterative Amplitude Adapted Fourier Transform algorithm [Venema et al., 2006], which involves phase randomizing the original field using a two-dimensional Fourier transform. This algorithm preserves the spatial autocorrelation structure [Theiler et al., 1992] as well as the distribution of the original field. We then compute the correlation between the EBM estimate of $\Delta T_{i, j}$ based on the surrogate field and the $\Delta T_{i, j}$ produced in the AM2.1 simulation. This process is repeated 10,000 times to provide a null distribution against which the correlation obtained from using the actual Relative Land Influence field is compared. We present one-sided $p$ values because a positive relationship between the observed and modeled temperature change is expected.

The primary residual between the EBM and AM2.1 is that the EBM shows less warming as a function of latitude, overestimating warming at lower latitude and underestimating it at higher latitudes. The crossover point occurs between 40 and $45^{\circ}$ in both hemispheres. On average, the EBM overestimates the warming by $0.06^{\circ} \mathrm{C}\left(0.02^{\circ} \mathrm{C}\right)$ at latitudes below this crossover point and underestimates it by $0.07^{\circ} \mathrm{C}\left(0.02^{\circ} \mathrm{C}\right)$ above this point in the Northern (Southern) Hemisphere. Additionally, the ratio of land to ocean warming is greater in the AM2.1 simulation (6.7) than in the EBM (4.8), suggesting that the EBM may overestimate the magnitude of heat fluxes from land to ocean. Finally, the warming over central South America is overestimated. Misfit in this region is also apparent for the seasonal cycle case and the multidecadal predictions considered in the next section. The origin of this misfit may stem from misspecification of Relative Land Influence because of biases in the NCEP-DOE reanalysis related to poor representation of the effects of the Andes [e.g., Rusticucci and Kousky, 2002].

\section{Interpretation of Recent Decadal Trends}

Having tuned the EBM to the seasonal cycle and demonstrated skill in reproducing simulated equilibrium conditions, we now turn to comparing the EBM results to observed temperature changes since 1950, interpreted as a response to a trend in radiative forcing. Other influences on temperature such as land use changes, spatial variability in forcing or feedbacks, and variations in circulation are not accounted for.

Based on equations (4) and (5), assigning zero temperature change at some time $t_{0}$ and assuming that radiative forcing increases at a constant rate $\beta$, the temperature change at $t_{1}$ is

$$
\Delta T_{i, j}=m_{i, j}\left[\frac{\beta C_{\text {land }}}{\lambda^{2}}\left[\exp \left[\frac{\lambda t_{1}}{C_{\text {land }}}\right]-1\right]\right]+\left(1-m_{i, j}\right)\left[\frac{\beta C_{\text {ocean }}}{(\lambda-\kappa)^{2}}\left[\exp \left[\frac{(\lambda-\kappa) t_{1}}{C_{\text {ocean }}}\right]-1\right]\right]-\frac{\beta t_{1}}{\lambda}
$$

The final term, $-\frac{\beta t_{1}}{\lambda}$, is equivalent to the equilibrated case in equation (7). The first and second terms are the transient damping induced by land and ocean heat uptake, though the small heat capacity of the land makes the first term negligible. The only free model parameters are $\lambda$ and $\kappa$, which are chosen based on minimizing the sum of squared deviations across gridboxes between the EBM and the observations. The heat capacities and Relative Land Influence field are fixed to the values used in the seasonal cycle analysis. Like the AM2.1 scenario, meridional heat flux anomalies are not included. 

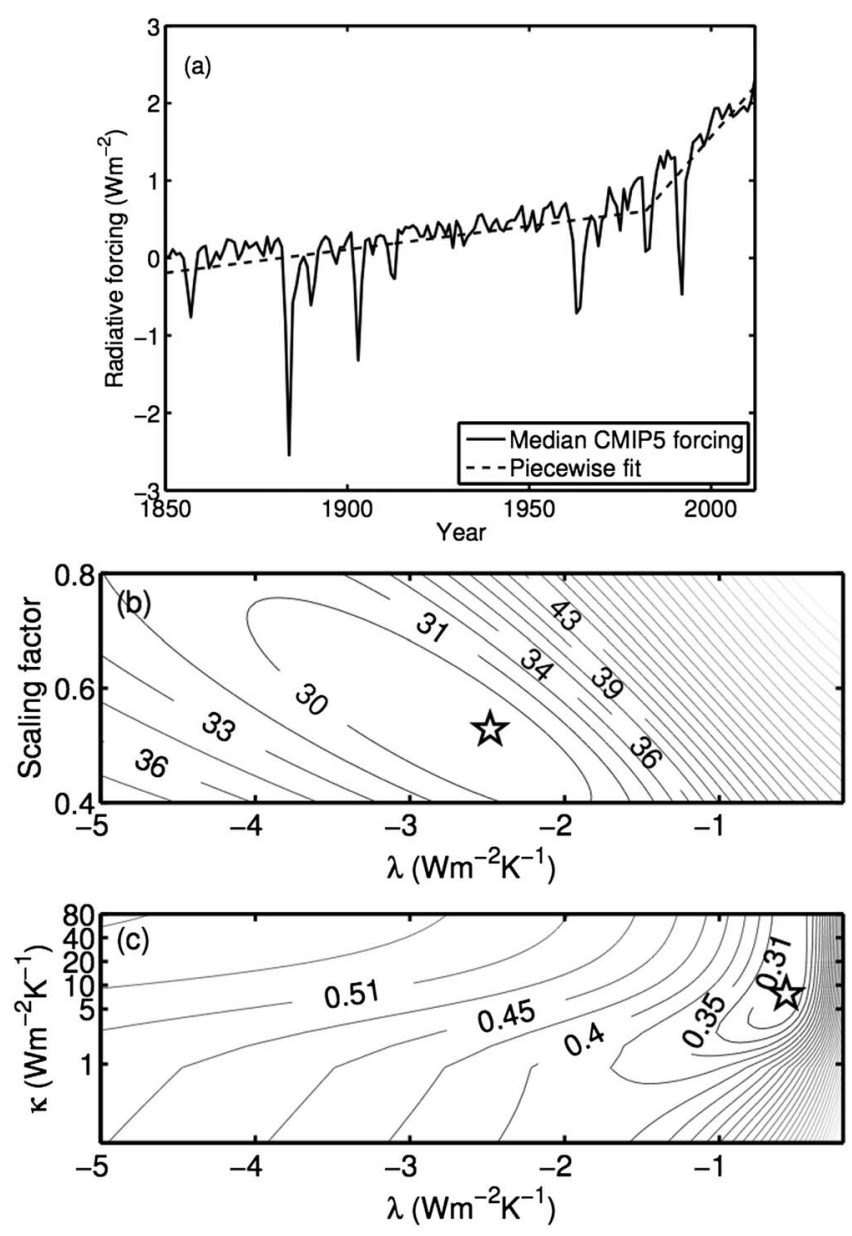

Figure 2. Radiative forcing and time scale-dependent sensitivity. (a) Median CMIP5 radiative forcing (natural and anthropogenic) from Forster et al. [2013] and the piecewise linear fit used to force the EBM for multidecadal temperature change. (b) The root-mean-square deviation (RMSD, in $\left.{ }^{\circ} \mathrm{C}\left(\mathrm{kWm}^{-2}\right)^{-1}\right)$ between the EBM and the observed gain as a function of $\lambda$ and the scaling factor, $k$, for Relative Land Influence (see section 2.2). The seasonal cycle model is insensitive to the value of $\kappa$, which is set to zero. (c) The RMSD $\left({ }^{\circ} \mathrm{C}\right)$ for $1950-2012$ temperature change as a function of $\lambda$ and $\kappa$. In both Figures $2 \mathrm{~b}$ and $2 \mathrm{c}$, the black star indicates the best fit value for the EBM.

of intervals ranging in length from 10 to 30 years, where the second interval must end in 2012, but the first interval can begin as early as 1900 (Figure S3). The correlation declines for earlier intervals when fewer gridboxes meet the inclusion criteria, as well as for shorter intervals spanning the recent past, presumably because the ratio of interannual variability in temperature to the temperature response radiative forcing is larger. The correlation between the EBM estimate of $\Delta T_{i, j}$ and the observations remains significant when individually considering ocean $(r=0.28$ and $p$ value $<0.03$ ) or land $(r=0.52$ and $p$ value $<0.04)$, indicating skill beyond the first-order land/ocean contrast. The correlation over the ocean is lower than over land, likely because the EBM lacks representation of ocean heat transport and changes in mixed layer depth.

Consistent with the previous work using observations to determine climate parameters [e.g., Forest et al., 2002], the linear diffusivity, $\kappa$, which parameterizes deep ocean heat uptake, is only weakly constrained (see Table 1). Note that our definition of $\kappa$ (equation (3)) scales the change in temperature of the ocean end-member to calculate ocean heat uptake rather than the global mean temperature change, as is done in Gregory and Forster [2008].

Although we do not expect the global ocean heat uptake anomalies calculated by the EBM to be accurate because the model is constrained using only extratropical data and does not account for ocean dynamics, 

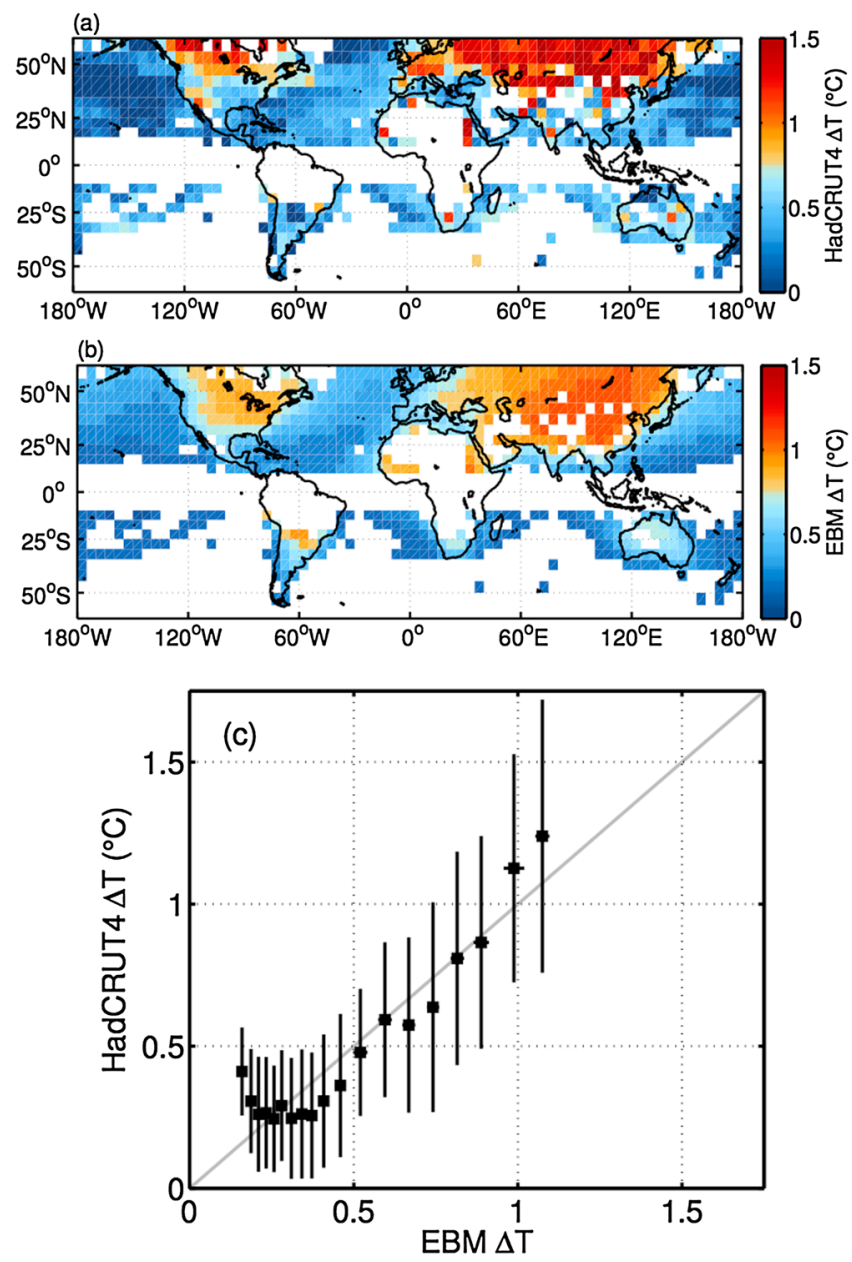

Figure 3. As in Figure 1 but for the observed change in temperature in the HadCRUT4 data set between 1950 and 2012.

occurs between 40 and $45^{\circ}$, with an average overestimation in the lower latitudes of $0.12^{\circ} \mathrm{C}$ and an average overestimation in the higher latitudes of $0.11^{\circ} \mathrm{C}$ in the Northern Hemisphere. Whether meridional patterns in Southern Hemisphere residuals exist is unclear because the data are sparse.

\section{Discussion and Conclusions}

The significance of the relationship between the patterns of warming predicted by the EBM and those from an atmospheric GCM equilibrium simulation and observed over the past half century suggest that there may be value in interpreting the inferred values of the feedback parameter, $\lambda$. The value of $\lambda$, however, is not strictly comparable to estimates of effective sensitivity in climate models because the domain we consider is not global in scope; therefore, $\lambda$ incorporates the influence of any heat fluxes into or out of the domain. Instead, this feedback parameter is a metric of the temperature sensitivity to radiative forcing in the extratropics. The value of $\lambda,-0.57 \pm 0.04$, found from fitting our model to the instrumental record exceeds the upper value of the CMIP3 estimates [Soden and Held, 2006], which range from -1.64 to $-0.88 \mathrm{Wm}^{-2} \mathrm{~K}^{-1}$. The difference could either reflect heat flux convergence into the extratropics or a more sensitive extratropics as compared to the globe. The AM2.1 feedback parameter, $-2.09 \pm 0.09 \mathrm{Wm}^{-2} \mathrm{~K}^{-1}$, is more negative than that found for the coupled version of the model, CM2.1, of $-1.37 \mathrm{Wm}^{-2} \mathrm{~K}^{-1}$ [Soden and Held, 2006], possibly reflecting the fact that fixing ocean surface temperature in AM2.1 limits the strength of positive feedbacks, like the water vapor feedback.

The analysis also suggests that the magnitude of the feedback parameter depends on the time scale under consideration. The feedback parameter for the seasonal cycle is significantly more negative than that for the 
1950-2012 temperature change. This difference in sensitivity is not simply due to the different magnitude of ocean heat uptake on seasonal versus longer time scales because the EBM's feedback parameter and ocean diffusivity are jointly constrained by the observations (Figures $2 b$ and $2 c$ ). Such time scale-dependent differences in feedback strength have been found for the water vapor and lapse rate feedbacks in GCMs [Colman and Hanson, 2013], as well as the total feedback parameter over the oceans based on an analysis of observations and reanalysis [Bony et al., 1995]. A separate application of radiative kernels [Shell et al., 2008] to National Center for Atmospheric Research Community Climate System Model version 4 (CCSM4) also suggests that the net feedback for the seasonal cycle is more negative than that for the response to ramped radiative forcing.

Although the intentionally simple nature of the EBM allows for ease of interpretability, there are substantial limitations. A diversity of important climate processes were explicitly excluded such as possible changes in meridional heat transport, spatial variability in radiative forcing, spatial or temporal structure in the ocean's mixed layer, and land cover distributions and their changes. We cannot conclusively attribute model residuals to any of these processes or ensure that the strength of the model fit is not in part due to coincidental cancelation of processes not modeled. Other consideration include that we cannot apply this model in the deep tropics because tuning relies on the presence of a strong once-per-year season cycle and that our metric of Relative Land Influence would be compromised by changes in atmospheric circulation.

It appears, however, that this minimalist model at least partially captures the advective land-ocean heat fluxes that lead to similar patterns of variability at different time scales. This result may seem surprising given the substantial spatial structures in forcing and feedbacks [Zelinka and Hartmann, 2012; Armour et al., 2013] but may result from horizontal heat transport diverging heat away from regions experiencing larger forcing and/or less negative feedbacks. Such an effect has been shown using aquaplanet simulations in which temperature changes due to feedbacks are strongly anticorrelated with those due to transport [Feldl and Roe, 2013]. The meridional structure of the residuals between the EBM predictions and the AM2.1 simulation, as well as the HadCRUT4 observations, are consistent with simulations showing increased poleward heat transport in response to increased radiative forcing, with the switch from divergence to convergence occurring around $40-45^{\circ} \mathrm{N}$ in model simulations [Held and Soden, 2006].

The interpretability of the equilibrium and multidecadal patterns of temperature change predicted by the EBM suggests that the repeatedly observed seasonal cycle contains valuable information for constraining and understanding longer-term temperature responses to radiative forcing. In future work, it would be useful to further explore similarities between seasonal and longer-term temperature variability in the context of more complete models.

Acknowledgments

The Relative Land Influence field and code to reproduce the figures in this paper are available as supporting information at people. fas.harvard.edu/ phuybers/Doc/ McKinnonHuybers2014. We thank Aaron Donohoe, Kyle Armour, and Cecilia Bitz for their helpful comments on the manuscript, Isaac Held for providing the AM2.1 model output, and two anonymous reviewers for their helpful suggestions. The calculation of seasonal feedbacks in CCSM4 was undertaken in collaboration with Cecilia Bitz during a visit by K.A.M. to the University of Washington. K.A.M. was supported by the NSF GRFP, and P.H. was supported by NSF grant 1304309.

The Editor thanks two anonymous reviewers for their assistance in evaluating this paper.

\section{References}

Armour, K. C., C. M. Bitz, and G. H. Roe (2013), Time-varying climate sensitivity from regional feedbacks, J. Clim., 26(13), 4518-4534. Bony, S., J.-P. Duvel, and H. Le Trent (1995), Observed dependence of the water vapor and clear-sky greenhouse effect on sea surface temperature: Comparison with climate warming experiments, Clim. Dyn., 11(5), 307-320.

Colman, R., and L. Hanson (2013), On atmospheric radiative feedbacks associated with climate variability and change, Clim. Dyn., 40(1-2), 475-492.

Donohoe, A., and D. S. Battisti (2013), The seasonal cycle of atmospheric heating and temperature, J. Clim., 26(14), $4962-4980$.

Draxler, R. (1997), HYSPLIT_4 user's guide, NOAA Tech. Memo ERL ARL-230, NOAA Air Resources Laboratory, Silver Spring, Md.

Draxler, R., and G. Hess (1997), Description of the HYSPLIT_4 modeling system, NOAA Tech. Memo ERL ARL-224, NOAA Air Resources Laboratory, Silver Spring, Md.

Draxler, R., and G. Hess (1998), An overview of the HYSPLIT_4 modelling system for trajectories, dispersion, and deposition, Aust. Meteorol. Mag., 47(4), 295-308.

Fasullo, J. T., and K. E. Trenberth (2008), The annual cycle of the energy budget. Part II: Meridional structures and poleward transports, J. Clim., 21(10), 2313-2325.

Feldl, N., and G. H. Roe (2013), The nonlinear and nonlocal nature of climate feedbacks, J. Clim., 21(21), 8289-8304.

Forest, C. E., P. H. Stone, A. P. Sokolov, M. R. Allen, and M. D. Webster (2002), Quantifying uncertainties in climate system properties with the use of recent climate observations, Science, 295(5552), 113-117.

Forster, P. M., T. Andrews, P. Good, J. M. Gregory, L. S. Jackson, and M. Zelinka (2013), Evaluating adjusted forcing and model spread for historical and future scenarios in the CMIP5 generation of climate models, J. Geophys. Res. Atmos., 118, 1139-1150, doi:10.1002/jgrd.50174.

Gregory, J., and P. Forster (2008), Transient climate response estimated from radiative forcing and observed temperature change, J. Geophys. Res., 113, D23105, doi:10.1029/2008JD010405.

Held, I. M., and B. J. Soden (2006), Robust responses of the hydrological cycle to global warming, J. Clim., 19(21), 5686-5699.

Held, I. M., M. Winton, K. Takahashi, T. Delworth, F. Zeng, and G. K. Vallis (2010), Probing the fast and slow components of global warming by returning abruptly to preindustrial forcing, J. Clim., 23(9), 2418-2427.

Huybers, P., and W. Curry (2006), Links between annual, Milankovitch and continuum temperature variability, Nature, 441(7091), 329-332. 
Hwang, Y.-T., D. M. Frierson, and J. E. Kay (2011), Coupling between Arctic feedbacks and changes in poleward energy transport, Geophys. Res. Lett., 38, L17704, doi:10.1029/2011GL048546.

Kanamitsu, M., W. Ebisuzaki, J. Woollen, S.-K. Yang, J. Hnilo, M. Fiorino, and G. Potter (2002), NCEP-DOE AMIP-II reanalysis (R-2), Bull. Am. Meteorol. Soc., 83(11), 1631-1643.

Kim, K.-Y., and G. R. North (1991), Surface temperature fluctuations in a stochastic climate model, J. Geophys. Res., 96(D10), 18,573-18,580.

Kim, K.-Y., G. R. North, and J. Huang (1992), On the transient response of a simple coupled climate system, J. Geophys. Res., 97(D9), 10,069-10,081.

Knutti, R., G. A. Meehl, M. R. Allen, and D. A. Stainforth (2006), Constraining climate sensitivity from the seasonal cycle in surface temperature, J. Clim., 19(17), 4224-4233.

Loeb, N. G., B. A. Wielicki, D. R. Doelling, G. L. Smith, D. F. Keyes, S. Kato, N. Manalo-Smith, and T. Wong (2009), Toward optimal closure of the Earth's top-of-atmosphere radiation budget, J. Clim., 22(3), 748-766.

Loeb, N. G., J. M. Lyman, G. C. Johnson, R. P. Allan, D. R. Doelling, T. Wong, B. J. Soden, and G. L. Stephens (2012), Observed changes in top-of-the-atmosphere radiation and upper-ocean heating consistent within uncertainty, Nat. Geosci., 5(2), 110-113.

Lyman, J. M., S. A. Good, V. V. Gouretski, M. Ishii, G. C. Johnson, M. D. Palmer, D. M. Smith, and J. K. Willis (2010), Robust warming of the global upper ocean, Nature, 465(7296), 334-337.

Manabe, S., R. Stouffer, M. Spelman, and K. Bryan (1991), Transient responses of a coupled ocean-atmosphere model to gradual changes of atmospheric $\mathrm{CO}_{2}$. Part I. Annual mean response, J. Clim., 4(8), 785-818.

McKinnon, K. A., A. R. Stine, and P. Huybers (2013), The spatial structure of the annual cycle in surface temperature: Amplitude, phase, and Lagrangian history, J. Clim., 26(20), 7852-7862.

Morice, C. P., J. J. Kennedy, N. A. Rayner, and P. D. Jones (2012), Quantifying uncertainties in global and regional temperature change using an ensemble of observational estimates: The HadCRUT4 data set, J. Geophys. Res., 117, D08101, doi:10.1029/2011JD017187.

North, G., and J. Coakley (1979), Differences between seasonal and mean annual energy balance model calculations of climate and climate sensitivity, J. Atmos. Sci., 36(7), 1189-1204.

North, G. R., R. F. Cahalan, and J. A. Coakley (1981), Energy balance climate models, Rev. Geophys., 19(1), 91-121.

Otto, A., et al. (2013), Energy budget constraints on climate response, Nat. Geosci., 6(6), 415-416.

Purkey, S. G., and G. C. Johnson (2010), Warming of global abyssal and deep southern ocean waters between the 1990s and 2000s: Contributions to global heat and sea level rise budgets, J. Clim., 23(23), 6336-6351.

Raper, S. C., J. M. Gregory, and R. J. Stouffer (2002), The role of climate sensitivity and ocean heat uptake on AOGCM transient temperature response, J. Clim., 15(1), 124-130.

Rusticucci, M. M., and V. E. Kousky (2002), A comparative study of maximum and minimum temperatures over argentina: NCEP-NCAR reanalysis versus station data, J. Clim., 15(15), 2089-2101.

Shell, K. M., J. T. Kiehl, and C. A. Shields (2008), Using the radiative kernel technique to calculate climate feedbacks in NCAR's Community Atmospheric Model, J. Clim., 21(10), 2269-2282.

Sobel, A. H., J. Nilsson, and L. M. Polvani (2001), The weak temperature gradient approximation and balanced tropical moisture waves, J. Atmos. Sci., 58(23), 3650-3665.

Soden, B. J., and I. M. Held (2006), An assessment of climate feedbacks in coupled ocean-atmosphere models, J. Clim., 19(14), 3354-3360. Stine, A., P. Huybers, and I. Fung (2009), Changes in the phase of the annual cycle of surface temperature, Nature, 457(7228), 435-440.

Stouffer, R., S. Manabe, and K. Bryan (1989), Interhemispheric asymmetry in climate response to a gradual increase of atmospheric $\mathrm{CO}_{2}$, Nature, 342(6250), 660-662.

The GFDL Global Atmospheric Model Development Team (2004), The new GFDL global atmosphere and land model AM2-LM2: Evaluation with prescribed SST simulations, J. Clim., 17(24), 4641-4673.

Theiler, J., S. Eubank, A. Longtin, B. Galdrikian, and J. Doyne Farmer (1992), Testing for nonlinearity in time series: The method of surrogate data, Physica $D, 58(1), 77-94$.

Thomson, D. J. (1995), The seasons, global temperature, and precession, Science, 268(5207), 59-68.

Venema, V., S. Meyer, S. G. García, A. Kniffka, C. Simmer, S. Crewell, U. Löhnert, T. Trautmann, and A. Macke (2006), Surrogate cloud fields generated with the iterative amplitude adapted Fourier transform algorithm, Tellus A, 58(1), 104-120.

Wigley, T., and M. Schlesinger (1985), Analytical solution for the effect of increasing $\mathrm{CO}_{2}$ on global mean temperature, Nature, 315, 649-652.

Wunsch, C., and P. Heimbach (2014), Bidecadal thermal changes in the abyssal ocean, J. Phys. Oceanogr., doi:10.1175/JPO-D-13-096.1.

Zelinka, M. D., and D. L. Hartmann (2012), Climate feedbacks and their implications for poleward energy flux changes in a warming climate, J. Clim., 25(2), 608-624. 